\title{
Developmental origins of health and adult disease: What should neonatologists/paediatricians be considering about the long-term health of their patients?
}

\author{
Alison L Kent ${ }^{1,2}$ \\ 'Department of Neonatology, Canberra Hospital, Woden and ${ }^{2}$ Australian National University Medical School, Canberra, Australian Capital Territory, Australia
}

\begin{abstract}
The developmental origins of health and disease hypothesis is now strongly supported by both animal and human evidence, and as a consequence, obstetricians, neonatologists and paediatricians need to consider the impact that the in utero and early post-natal environment can have on later renal, cardiovascular and metabolic health. Four common clinical scenarios were provided along with animal and human evidence identifying long-term health implications. Suggestions as to how we should translate this growing body of evidence into practice are provided.
\end{abstract}

Key words: cardiovascular; developmental origins; metabolic; neonate; premature.

Since Barker first hypothesised that fetal growth had an influence on long-term cardiovascular outcome, there is now mounting evidence to support the hypothesis. ${ }^{1,2}$ Given this, what should our focus be as neonatologists and paediatricians to ensure that our patients have as healthy a start to life as possible and minimise long-term health risks?

\section{Clinical Scenario 1}

Consider a premature male infant born at 26 weeks gestation weighing $880 \mathrm{~g}$ (50th percentile) delivered without the benefit of antenatal steroids with evidence of chorioamnionitis and funisitis on placental examination. In the first few days of life, he is noted to have a patent ductus arteriosus (PDA) and is treated with indomethacin for 6 days. He is able to be extubated and commences on oral feeds. On day 10, he deteriorates with increasing apnoeas and bradycardias and evidence of sepsis. He is re-intubated and increasing abdominal distension is noted

\section{Key Points \\ 1 Nutritional status in utero and the early post-natal period has implications for long-term cardiovascular health. \\ 2 Premature infants are exposed to a number of insults post- natally that may affect glomerulogenesis and long-term renal health. \\ 3 Ex-premature neonates should have their blood pressure checked routinely throughout childhood and into adulthood.}

Correspondence: Associate Professor Alison Kent, Department of Neonatology, Canberra Hospital, PO Box 11, Woden, ACT 2606, Australia. Fax: +61 26244 3112; email: alison.kent@act.gov.au

Conflict of interest: None declared.

Accepted for publication 5 July 2012. with discolouration of the abdominal wall. An abdominal X-ray reveals free gas, and at laparotomy, a jejunostomy is formed for necrotising enterocolitis. He recovers but requires prolonged total parenteral nutrition, and his discharge weight is on the 10th centile with length and head circumference on the third centile. What risk factors are there for long-term cardiovascular/ renal consequences?

Much neonatal research has focused on brain and lung injury as they obviously have significant impact on long-term neurodevelopmental outcome and mortality; however, long-term cardiovascular health is now becoming an important consideration. With the developmental origins of health and disease hypothesis gaining momentum, research in both animal and human studies is indicating potential fetal/post-natal programming of renal function. Galinsky et al. have shown that in the preterm fetal sheep model, exposure to chorioamnionitis results in reduced nephron number. ${ }^{3}$ Prenatal glucocorticoid exposure in the fetal sheep model also results in reduced nephron number and hypertension in the adult sheep. ${ }^{4,5}$ However, this animal evidence has not necessarily translated into human findings, with evidence being variable as to antenatal steroid exposure and later hypertension. ${ }^{6-9}$ However, three of these studies were in children/young adults less than 19 years old where hypertension may not yet have occurred. These studies did find differences in systolic blood pressure (BP) and glomerular filtration rates, which may result in later hypertension and renal compromise. Given the overall significant mortality and morbidity benefits of antenatal corticosteroids however, withholding antenatal steroids with the view to reduce potential long-term cardiovascular risk is not an option. Research into ways to mitigate the long-term health risk caused by antenatal steroids needs to be pursued.

Exposure to post-natal indomethacin for treatment of a PDA may also have long-term implications. Up to $25 \%$ of neonates 
exposed to indomethacin suffer acute renal failure. ${ }^{10}$ In a neonatal rat model, exposure to indomethacin and ibuprofen showed significant glomerular injury on electron microscopic examination but at 14 days did not reduce glomerular number. ${ }^{11,12}$ A recent study has shown increased numbers of podocytes in the urine of preterm neonates receiving indomethacin, suggesting that the drug induces glomerular injury at this critical time of ongoing glomerulogenesis. ${ }^{13}$ At present, intravenous indomethacin or ibuprofen are the drugs of choice to close a PDA. However, new studies into paracetamol as an alternative may present neonatologists with a safer option abrogating renal risk. ${ }^{14}$

The entity of preterm birth itself may result in reduced nephron numbers increasing risks of later renal and hypertensive disease. Gubhaju et al. have shown altered glomerular structure in $0.2-18 \%$ of glomeruli in the outer renal cortex of preterm baboons, which may have long-term implications on renal health. ${ }^{15}$ A recent premature mice study has shown a reduction in nephron number solely related to prematurity, which was associated with reduced glomerular filtration rate (GFR), proteinuria and adult hypertension. ${ }^{16}$ In a post-mortem study of human neonatal kidneys, those born premature and surviving for a period of time were shown to have accelerated maturation and abnormal glomerular morphology in comparison with stillbirth controls at the same gestation. ${ }^{17}$ Although there was no evidence of decreased renal volume in preterm infants at term-corrected age, ${ }^{18}$ a separate study has shown that at 20 years of age, the left kidney length and volume was smaller in preterm infants than term controls, particularly in females. ${ }^{19}$ As an extension of these histological and morphological findings, elevated BP has been found in a number of studies of extremely preterm babies at a variety of ages. ${ }^{20-22}$

\section{Clinical Scenario 2}

Another common clinical scenario is the neonate that is delivered at 32 weeks gestation weighing $1000 \mathrm{~g}$ (<third centile) after an antenatal ultrasound showing reverse diastolic flow. The baby is commenced on feeds, and after a period of feed intolerance, progresses to full feeds and is eventually discharged home weighing $2500 \mathrm{~g}$ at 44 weeks gestation (<third centile). What factors place this baby at long-term cardiovascular/renal risk?

In utero growth restriction (IUGR) is now implicated in many health conditions later in life including obesity, insulin resistance, hypertension and diabetes. ${ }^{23}$ There are a number of animal studies using uterine artery ligation as a model for IUGR looking at metabolic and renal consequences. ${ }^{24-26}$ Protein restriction is another method used in animal studies to produce IUGR in the offspring to look at cardiovascular and renal consequences. ${ }^{27-29}$ Nephron number has been associated with progression of renal disease and hypertension in human adults in two studies, ${ }^{30,31}$ and there are now a number of studies indicating that low birthweight contributes to end-stage renal disease. ${ }^{32-35}$ There is, unfortunately, no non-invasive way of determining nephron number in the living human. Since the first papers by Barker, Hales et al. and Osmond et al., ${ }^{36-38}$ the number of studies associating low birthweight with cardiovas- cular disease and diabetes have increased with a number of reviews and systematic analyses confirming the relationship. ${ }^{39-42}$

\section{Clinical Scenario 3}

Unfortunately, this scenario is becoming increasingly frequent. A term baby is delivered weighing $2.1 \mathrm{~kg}$ at 36 weeks gestation to a woman with a body mass index (BMI) of 45, gestational diabetes and pre-eclampsia. The placenta showed evidence of chorangiosis and accelerated maturation with increased syncytial knot formation. Again, there are a number of potential risks for this baby for long-term metabolic and cardiovascular compromise.

This clinical example had two potential sets of adverse fetal outcomes: those associated with the growth-restricted baby described or those associated with the macrosomic neonate. With obesity becoming a major health problem in pregnant women, the added complication of gestational diabetes is a frequent finding. A recent large Swedish study has found that gestational diabetes resulted in a higher BMI in an 18-year-old male offspring, independent of maternal BMI. ${ }^{43}$ This has also been found in a study from Jerusalem where offspring at 17 years of age were found to have a higher BMI and $\mathrm{BP}^{44}$ However, these findings have not been replicated in other studies, ${ }^{45,46}$ and a recent systematic review has not found a consistent finding of gestational diabetes with obesity in offspring. ${ }^{47}$

Maternal obesity is related to poorer outcomes for both the mother and the fetus and is becoming a significant concern for later cardiovascular and metabolic outcomes. ${ }^{48}$ Zhang et al. reviewed the animal evidence for maternal over-nutrition and peri-conceptional weight changes and resulting metabolic outcomes. ${ }^{49}$ Maternal diabetes and pre-eclampsia appear to have an effect on BP in the first year of life, and this is particularly evident in those where placental dysfunction was noted on histology. ${ }^{50}$ Birthweight has been shown to increase with both increasing maternal BMI and weight gain during pregnancy, ${ }^{51}$ and recently, two studies have shown that maternal obesity in pregnancy increases the risk of obesity in children 2 to 4 years of age. ${ }^{52,53}$ A recent cross-generational study has shown an association of maternal BMI enduring over three generations. ${ }^{54}$ The human evidence now available is supporting the findings of animal models where maternal obesity has long-lasting implications on metabolic and cardiovascular outcomes of the offspring that may last for generations.

With these three case scenarios, there is then the issue of 'catch-up growth'. What is catch-up growth? Who does this apply to and should we be aiming for it? In the appropriately grown (10th-90th centile) premature neonate who has poor nutritional intake post-natally and falls below his or her original birth centile, the definition of catch-up growth has some conceptual framework for where that child's growth should be. However, for small for gestational age (SGA) infants, the centile at which they should have been born on is unknown unless regular in utero growth scans prior to the timing of onset of the growth restriction exist, indicating their original growth potential. It is likely that long-term renal dysfunction and hypertension is a consequence of multiple hits to the developing kidney, and one of these insults includes this notion of 'catch-up growth'. Catch-up growth in preterm infants, including 
head circumference, is related to improved neurological outcomes. ${ }^{55-58}$ True catch-up growth in the appropriate for gestational age premature neonate with post-natal growth restriction may be appropriate terminology and an important goal in the early neonatal period. These neonates should be considered differently to the SGA neonate as the long-term cardiovascular and metabolic consequences are concerning in those born SGA who have 'catch-up growth'. ${ }^{59-71}$ For the SGA infant, perhaps a more accurate description is weight gain above birth centile. It is not entirely clear from these studies at which point weight gain above birth centile in the SGA child is most deleterious, but continued rapid weight gain after 2 years of age may be problematic, while continued poor growth in the first year of life also appears to be harmful.

\section{Clinical Scenario 4}

While attending a conference in Santiago, Chile, you visit a hospital clinic where you see a 6-year-old child with asthma. She was born to a mother from a poor rural centre, who prior to pregnancy had a BMI of 19. Her daughter had a birthweight of $2.7 \mathrm{~kg}$ at 39 weeks gestation (fifth centile). Since moving to Santiago, their diet has changed and she now weighs $26 \mathrm{~kg}$ (>90th centile). What potential long-term risks are there for this child?

This scenario is becoming more common in developing countries and has the potential to stretch already restricted medical resources. Stein et al. reviewed cohort studies from developing countries, which have looked at metabolic outcomes into adulthood..$^{72-76}$ Continued growth failure in early childhood with increased weight gain in later childhood is associated with risk factors for cardiovascular disease including hypertension, glucose intolerance and body adiposity. Adaptations that have occurred to ensure survival during restricted nutrient supply become maladaptive when over nutrition occurs. ${ }^{77,78}$ The World Health Organization/Food and Agriculture Organization (WHO/ FAO) report on 'Diet, Nutrition and the Prevention of Chronic Diseases' in 2003 predicted that obesity-related type 2 diabetes would become a global epidemic. ${ }^{79}$ As a consequence, developing countries with stretched medical resources will now have to contend with the burden of chronic life-style diseases as well as infectious diseases.

\section{Closing Comments}

These four examples are situations that neonatologists and paediatricians face on a daily basis. As neonatal intensive care has improved, increasing numbers of extremely premature infants are surviving with reduced morbidity, and consideration must be given not only to their neurological outcome but long-term health consequences as well. It is difficult to extrapolate from the evidence available interventions during the neonatal period for the extremely premature neonate to minimise long-term health risks. However, with the available evidence trying to minimise known risk factors, as much as possible would be a logical approach. Attempting to reduce those risks would include minimising exposure to nephrotoxic drugs during glomerulogenesis, such as indomethacin and ibuprofen, and maximising nutrition to ensure that premature neonates grow along their percentiles so that catch-up growth is not required. The SGA neonate should be considered differently from the extremely premature neonate, and weight gain above their birth centile during the first 2 years of life may be appropriate while avoiding rapid growth after the first 2 years of life. Parental awareness of the potential long-term health consequences of extreme prematurity and growth restriction is required, with focus placed on a healthy life-style continuing once the neonate is discharged home. Primary prevention continues to be of importance but frequently the most difficult to provide due to time restrictions and a lack of focus on child cardiovascular health. The incidence of hypertension in children is increasing and ranges from $1 \%$ to $10 \%,{ }^{80}$ but BP measurement in children is infrequently performed, and if done, elevated levels often go unrecognised.$^{81}$ Discussing cardiovascular risk and obesity needs to start early in these particularly vulnerable groups of children to minimise long-term health sequelae.

\section{Acknowledgements}

Thank you to Dr Nahal Payman and Assistant Professor Chris Nolan for providing advice on this manuscript.

\section{References}

1 Barker DJP, Osmond C. Infant mortality, childhood, nutrition, and ischaemic heart disease in England and Wales. Lancet 1986; 1: 1077-81.

2 Barker DJP. Developmental origins of chronic disease. Public Health 2012; 126: 185-9.

3 Galinsky R, Moss TJ, Gubhaju L, Hooper SB, Black MJ, Polglase GR. Effect of intra-amniotic lipopolysaccharide on nephron number in preterm fetal sheep. Am. J. Physiol. Renal Physiol. 2011; 301: F280-5.

4 Wintour EM, Mortiz KM, Johnson K, Ricardo S, Samuel CS, Dodic M. Reduced nephron number in adult sheep, hypertensive as a result of prenatal glucocorticoid treatment. J. Physiol. 2003; 549: 929-35.

5 Mortiz KM, De Matteo R, Dodic M et al. Prenatal glucocorticoid exposure in the sheep alters renal development in utero: implications for adult renal function and blood pressure control. Am. J. Physiol. Regul. Integr. Comp. Physiol. 2011; 301: R500-9.

6 Doyle LW, Ford GW, Davis NM, Callanan C. Antenatal corticosteroid therapy and blood pressure at 14 years of age in preterm children. Clin. Sci. 2000; 98: 137-42.

7 Dalziel SR, Walker NK, Parag V et al. Cardiovascular risk factors after antenatal exposure to betamethasone: 30-year follow-up of a randomised controlled trial. Lancet 2005; 365: 1856-62.

8 Finken MJJ, Keijzer-Veen MG, Dekker FW et al., on behalf of the Dutch POPS-19 Collaborative Study Group. Antenatal glucocorticoid treatment is not associated with long-term metabolic risks in individuals born before 32 weeks of gestation. Arch. Dis. Child. Fetal Neonatal Ed. 2008; 93: F442-7.

9 Carballo-Magdaleno D, Guizar-Mendoza JM, Amador-Licona N, Dominguez-Dominguez $\mathrm{V}$. Renal function, renal volume, and blood pressure in infants with antecedent of antenatal steroids. Pediatr. Nephrol. 2011; 26: 1851-6.

10 Akima S, Kent A, Reynolds GJ, Gallagher M, Falk MC. Indomethacin and renal impairment in neonates. Pediatr. Nephrol. 2004; 19: 490-3.

11 Kent AL, Maxwell LE, Koina ME, Falk MC, Willenborg D, Dahlstrom JE. Renal glomeruli and tubular injury following indomethacin, ibuprofen, and gentamicin exposure in a neonatal rat model. Pediatr. Res. 2007; 62: 307-12. 
12 Kent AL, Douglas-Denton R, Shadbolt B et al. Indomethacin, ibuprofen and gentamicin administered during late stages of glomerulogenesis do not reduce glomerular number at 14 days of age in the neonatal rat. Pediatr. Nephrol. 2009; 24: 1143-9.

13 Kent AL, Brown L, Broom M, Broomfield A, Dahlstrom JE. Increased urinary podocytes following indomethacin suggests drug-induced glomerular injury. Pediatr. Nephrol. 2012; 27: 1111-7.

14 Hammerman C, Bin-Nun A, Markovitch A, Schimmel MS, Kaplan M, Fink D. Ductal closure with paracetamol: a surprising new approach to patent ductus arteriosus treatment. Pediatrics 2011; 128: e1618-21.

15 Gubhaju L, Sutherland MR, Yoder BA, Zulli A, Bertram JF, Black MJ. Is nephrogenesis affected by preterm birth? Studies in a non-human primate model. Am. J. Physiol. Renal Physiol. 2009; 297: F1668-77.

16 Stelloh C, Allen KP, Mattison DL, Lerch-Gaggl A, Reddy A, El-Meanawy A. Prematurity in mice leads to reduction in nephron number, hypertension, and proteinuria. Transl. Res. 2012; 159: 80-9.

17 Sutherland MR, Gubhaju L, Moore L et al. Accelerated maturation and abnormal morphology in the preterm neonatal kidney. J. Am. Soc. Nephrol. 2011; 22: 1365-74.

18 Kent AL, Jyoti R, Robertson $\mathrm{C}$ et al. Does extreme prematurity affect kidney volume at term corrected age? J. Matern. Fetal Neonatal Med. 2009; 22: 435-8.

19 Keijzer-Veen MG, Devos AS, Meradji M, Dekker FW, Nauta J, van der Heijden BJ. Reduced renal length and volume 20 years after very preterm birth. Pediatr. Nephrol. 2010; 25: 499-507.

20 Kistner A, Celsi G, Vanpee M, Jacobson SH. Increased systolic daily ambulatory blood pressure in adult women born preterm. Pediatr. Nephrol. 2005; 20: 232-3.

21 Keijzer-Veen MG, Dulger A, Dekker FW, Nauta J, van der Heijden BJ. Very preterm birth is a risk factor for increased systolic blood pressure at a young adult age. Pediatr. Nephrol. 2010; 25: 509-16.

22 Duncan AF, Heyne RJ, Morgan JS, Ahmad N, Rosenfeld CR. Elevated systolic blood pressure in preterm very-low-birth-weight infants $\leq 3$ years of life. Pediatr. Nephrol. 2011; 26: 1115-21.

23 Varvarigou AA. Intrauterine growth restriction as a potential risk factor for disease onset in adulthood. J. Pediatr. Endocrinol. Metab. 2010; 23: 215-24.

24 Stoffers DA, Desai BM, DeLeon DD, Simmons RA. Neonatal exendin-4 prevents the development of diabetes in the intrauterine growth retarded rat. Diabetes 2003; 52: 734-40.

25 Nusken K-D, Dotsch J, Rauh M, Rascher W, Schneider H Uteroplacental insufficiency after bilateral uterine artery ligation in the rat: impact on postnatal glucose and lipid metabolism and evidence for metabolic programming of the offspring by sham operation. Endocrinology 2008; 149: 1056-63.

26 Wlodek ME, Westcott K, Siebel AL, Owens JA, Moritz KM. Growth restriction before or after birth reduces nephron number and increases blood pressure in male rats. Kidney Int. 2008; 74: 187-95.

27 Elmes MJ, Gardner DS, Langley-Evans SC. Fetal exposure to a maternal low-protein diet is associated with altered left ventricular pressure response to ischaemia-perfusion injury. Br. J. Nutr. 2007; 98: 93-100.

28 Woods LL, Ingelfinger JR, Nyengaard JR, Rasch R. Maternal protein restriction suppresses the newborn renin-angiotensin system and programs adult hypertension in rats. Pediatr. Res. 2001; 49: 460-7.

29 Harrison M, Langley-Evans SC. Intergenerational programming of impaired nephrogenesis and hypertension in rats following maternal protein restriction during pregnancy. Br. J. Nutr. 2009; 101: 1020-30.

30 Keller G, Zimmer G, Mall G, Ritz E, Amann K. Nephron number in patients with primary hypertension. N. Engl. J. Med. 2003; 348 101-8.

31 Hoy WE, Hughson MD, Singh GR, Douglas-Denton R, Bertram JF. Reduced nephron number and glomerulomegaly in Australian Aborigines: a group at high risk for renal disease and hypertension. Kidney Int. 2006; 70: 104-10.
32 Lackland DT, Egan BM, Fran ZJ, Syddall HE. Low birth weight contributes to the excess prevalence of end-stage renal disease in African Americans. J. Clin. Hypertens. 2001; 3: 29-31.

33 Li S, Chen S-C, Shlipak M et al., on behalf of the Kidney Early Evaluation Program Investigators. Low birth weight is associated with chronic kidney disease only in men. Kidney Int. 2008; 73: 637-42.

34 Hallan S, Euser AM, Irgens LM, Finken MJJ, Holmen J, Dekker FW. Effect of intrauterine growth restriction on kidney function at young adult age: the Norf Trondelag Health (HUNT 2) Study. Am. J. Kidney Dis. 2007; 51: 10-20.

35 White SL, Perkovic V, Cass A et al. Is low birth weight an antecedent of CKD in later life? A systematic review of observational studies. Am J. Kidney Dis. 2009; 54: 248-61.

36 Barker DJ. The fetal origins of adult hypertension. J. Hypertens. 1992; 10 (Suppl.): S39-44.

37 Hales CN, Barker DJ, Clark PM et al. Fetal and infant growth and impaired glucose tolerance at age 64. BMJ 1991; 303: 1019-22.

38 Osmond C, Barker DJ, Winter PD, Fall CH, Simmonds SJ. Early growth and death from cardiovascular disease in women. BMJ 1993; 306: 422-6.

39 Hardy R, Sovio U, King VJ et al., the EURO-BLCS Study Group. Birthweight and blood pressure in five European birth cohort studies: an investigation of confounding factors. Eur. J. Public Health 2005; 16 : 21-30.

40 Nuyt AM. Mechanisms underlying developmental programming of elevated blood pressure and vascular dysfunction: evidence from human studies and experimental animal models. Clin. Sci. 2008; 114 $1-17$.

41 Nuyt AM, Alexander BT. Developmental programming and hypertension. Curr. Opin. Nephrol. Hypertens. 2009; 18: 14452.

42 Whincup PH, Kaye SJ, Owen CG et al. Birth weight and risk of type 2 diabetes: a systematic review. JAMA 2008; 300: 2886-97.

43 Lawlor DA, Lichtenstein P, Langstrom N. Association of maternal diabetes mellitus $n$ pregnancy with offspring adiposity into early adulthood. Circulation 2011; 123: 258-65.

44 Tsadok MA, Friedlander Y, Paltiel $\mathrm{O}$ et al. Obesity and blood pressure in 17-year-old offspring of mothers with gestational diabetes: insights from the Jerusalem perinatal study. Exp. Diabetes Res. 2011: [Epub ahead of print] doi: 10.1155/2011/906154.

45 Beyerlein A, Nehring I, Schaffrath Rosario A, von Kries R. Gestational diabetes and cardiovascular risk factors in the offspring: results from a cross-sectional study. Diabet. Med. 2012; 29: 378-84.

46 Patel S, Fraser A, Davey Smith G et al. Associations of gestational diabetes, existing diabetes, and glycosuria with offspring obesity and cardiometabolic outcomes. Diabetes Care 2012; 35: 63-71.

47 Kim SY, England JL, Sharma JA, Njoroge T. Gestational diabetes mellitus and risk of childhood overweight and obesity in offspring: a systematic review. Exp. Diabetes Res. 2011: [Epub ahead of print] doi:10.1155/2011/541308.

48 Poston L, Harthoorn LF, Van Der Beek EM, on behalf of contributors to the ILSI Workshop. Obesity in pregnancy: implications for the mother and lifelong health of the child. A consensus statement. Pediatr. Res. 2011; 69: 175-80.

49 Zhang S, Rattanatray L, Morrison JL, Nicholas LM, Lie S, McMillen IC. Maternal obesity and the early origins of childhood obesity: weighing up the benefits and costs of maternal weight loss in the periconceptional period for the offspring. Exp. Diabetes Res. 2011: [Epub ahead of print] doi:10.1155/2011/585749.

50 Kent AL, Shadbolt B, Hu E, Meskell S, Falk MC, Dahlstrom JE. Do maternal- or pregnancy-associated disease states affect blood pressure in the early neonatal period? Aust. N. Z. J. Obstet. Gynaecol. 2009; 49: 364-70. 
51 Stamnes Koepp UM, Frost Andersen L, Dahl-Jorgensen K, Stigum H, Nass $\mathrm{O}$, Nystad W. Maternal pre-pregnant body mass index, maternal weight change and offspring birthweight. Acta Obstet. Gynecol. Scand. 2012; 91: 243-9.

52 Olson CM, Demment MM, Carling SJ, Strawderman MS. Associations between mother's and their children's weights at 4 years of age. Child. Obes. 2010; 6: 201-7.

53 Whitaker RC. Predicting preschooler obesity at birth: the role of maternal obesity in early pregnancy. Pediatrics 2004; 114 : e29-36.

54 Murrin CM, Kelly GE, Tremblay RE, Kelleher CC. Body mass index and height over three generations: evidence from the Lifeways Cross-Generational Cohort Study. BMC Public Health 2012; 12: 81.

55 Martorell R, Horta BL, Adair LS et al., Consortium on Health Oriented Research in Transitional Societies Group. Weight gain in the first two years of life is an important predictor of schooling outcomes in pooled analyses from five birth cohorts from low- and middle-income countries. J. Nutr. 2010; 140: 348-54.

56 Ghods E, Kreissl A, Brandsetter S, Fuiko R, Widhalm K. Head circumference catch-up growth among preterm very low birth weight infants: effect on neurodevelopmental outcome. J. Perinat. Med. 2011; 39: 579-86.

57 Claas MJ, de Vries LS, Koopman C et al. Postnatal growth of preterm born children $\leq 750 \mathrm{~g}$ at birth. Early Hum. Dev. 2011; 87: 495-507.

58 Fattal-Valevski A, Toledano-Alhadef H, Leitner Y, Geva R, Eshel R, Harel S. Growth patterns in children with intrauterine growth retardation and their correlation to neurocognitive development. J. Child Neurol. 2009; 24: 846-51.

59 Forsen T, Eriksson J, Tuomilehto J, Reunanen A, Osmond C, Barker D. The fetal and childhood growth of persons who develop type 2 diabetes. Ann. Intern. Med. 2000; 133: 176-82.

60 Fagerberg B, Bondjers I, Nilsson P. Low birth weight in combination with catch-up growth predicts the occurrence of the metabolic syndrome in men at late middle age: the Atherosclerosis and Insulin Resistance Study. J. Intern. Med. 2004; 256: 254-9.

61 Mericq V, Ong KK, Bazaes R et al. Longitudinal changes in insulin sensitivity and secretion from birth to age three years in small- and appropriate-for-gestational-age children. Diabetologia 2003; 48 2609-14.

62 Ekelund U, Ong KK, Linne $Y$ et al. Association of weight gain in infancy and early childhood with metabolic risk in young adults. J. Clin. Endocrinol. Metab. 2007; 92: 98-103.

63 Ong KK, Ahmed MI, Emmett PM, Preece MA, Dunger DB. Association between postnatal catch-up growth and obesity in childhood: prospective cohort study. BMJ 2000; 320: 967-71.

64 Singhal A, Fewtrell M, Cole TJ, Lucas A. Low nutrient intake and early growth for later insulin resistance in adolescents born preterm. Lancet 2003; 361: 1089-97.

65 Soto N, Bazaes RA, Pena $\vee$ et al. Insulin sensitivity and secretion are related to catch-up-growth in small-for-gestational-age infants at age
1 year: results from a prospective cohort. J. Clin. Endocrinol. Metab. 2003; 88: 3645-50.

66 Singhal A, Cole TJ, Fewtrell $M$ et al. Promotion of faster weight gain in infants born small for gestational age: is there and adverse effect on blood pressure? Circulation 2007; 115: 213-20.

67 Erikssom JG, Forsen T, Tuomilehto J, Osmond C, Barker DJ. Early adiposity rebound in childhood and risk of type 2 diabetes in adult life. Diabetologia 2003; 46: 190-4.

68 Eriksson JG, Forsen T, Tuomilehto J, Osmond C, Barker DJ. Early growth and coronary heart disease in later life: longitudinal study. BMJ 2001; 322: 949-53.

69 Eriksson JG, Osmond C, Kajantie E, Forsen TJ, Barker DJ. Patterns of growth among children who later develop type 2 diabetes or its risk factors. Diabetologia 2003; 46: 190-4.

70 Ibanez L, Ong K, Dunger DB, De Zegher F. Early development of adiposity and insulin resistance after catch-up weight gain in small-for-gestational-age children. J. Clin. Endocrinol. Metab. 2006; 91: 2153-8

71 Deng H-Z, Li Y-H, Su Z et al. Association between height and weight catch-up growth with insulin resistance in pre-pubertal Chinese children born small for gestational age at two different ages. Eur. J. Pediatr. 2011; 170: 75-80.

72 Stein AD, Thompson AM, Waters A. Childhood growth and chronic disease: evidence from countries undergoing nutrition transition. Matern. Child Nutr. 2005; 1: 177-84.

73 Bhargava SK, Sachev HS, Fall CHD et al. Relation of serial changes in childhood body-mass index to impaired glucose tolerance in young adulthood. N. Engl. J. Med. 2004; 350: 865-75.

74 Martorell R, Habicht J-P, Rivera JA. History and design of the INCAP longitudinal study (1969-1977) and its follow-up (1988-1989). J. Nutr. 1995; 125 (Suppl. 4): S1027-41.

75 Victoria GC, Barros FC, Lima RC et al. The Pelotas birth cohort study. Rio Grande do Sul, Brazil, 1982-2001. Cad. Suade Publica 2003; 19 : 1241-56.

76 Adair LS, Cole TJ. Rapid child growth raised blood pressure in adolescent boys who were thin at birth. Hypertension 2003; 41 : 451-6.

77 Prentice AM. Intrauterine factors, adiposity, and hyperinsulinaemia. BMJ 2003; 327: 880-1.

78 Adair LS, Prentice AM. A critical evaluation of the fetal origins hypothesis and its implications for developing countries. J. Nutr. 2004; 134: 191-3

79 World Health Organization. Diet, nutrition and the prevention of chronic diseases. World Health Organ. Tech. Rep. Ser. 2003; 916: i-viii, 1-149.

80 Feber J, Ahmed M. Hypertension in children: new trends and challenges. Clin. Sci. 2010; 119: 151-61.

81 Brady TM, Solomon BS, Neu AM, Siberry GK, Parekh RS. Patient-, provider-, and clinic-level predictors of unrecognized elevated blood pressure in children. Pediatrics 2010; 125: e1286-93. 